\title{
A instrumentalização do clínico
}

\section{Clinical instruments development}

\section{Moara Ramos' ${ }^{\text {, Vânia Löschl Gapit }{ }^{1}, \text { Arnaldo Lichtenstein² }}$}

\begin{abstract}
Ramos M, Gapit VL, Lichtenstein A. A instrumentação do clínico. Rev Med (São Paulo). 2007 jan.-mar.;86(1):52-60.
\end{abstract}

RESUMO: Este artigo versa sobre os diferentes instrumentos clínicos que fazem parte do dia a dia da pratica medica e sobre como se tornaram partes essenciais da rotina de um profissional de saude.

DESCRITORES: Equipamentos e provisão. Médicos.

A palavra Clínica vem do grego klíne, leito, cama. Médico se dizia latrós ,e Klinikós era o médico que atendia os doentes acamados. Já a palavra cirurgia (khirourgia) é derivada do grego kheir, mão e ergon, trabalho.

Médico, do latim medicus, provém do latim medeor, derivado do verbo grego medeo, cuidar de.

\section{O pulso}

Foi Herófilo (300 a.C.), o primeiro anatomista e clínico ao mesmo tempo, fundador da doutrina do pulso, quem descreveu com exatidão as pulsações, correlacionou a sístole e a diástole com os sons musicais e considerou ser o pulso um fenômeno que ocorre dentro dos vasos. Herófilo também cunhou o termo pulso dicrótico (duplo batimento), comparandoo a um duplo salto de cabra, donde o nome pulsus caprizans.

Galeno(129-200 d. C.), entre as suas várias interpretações sobre o funcionamento do corpo humano, distinguiu entre o pulsus caprizans e o pulsus dicrotus: enquanto no primeiro ocorriam várias pulsações em uma sístole (salva extra-sistólica), no segundo ocorriam apenas duas (bigeminismo extrasistólico).

O estudante de medicina Galileu (1564-1643) constatou que o período de oscilação dos pêndulos é constante,independendo da amplitude dos movimentos.Como desprovia de relógios, usou suas próprias pulsações cardíacaspara realizar as medições. Sanctoruis Sanctorius (1561-1636), professor de Pádua e amigo de Galileu, em 1625 usou o pulsilógio (pêndulo feito por Galileu) para medir o pulso de seus pacientes.Esse instrumento foi aperfeiçoado por Sir John Floyer (1649-1734),. que criou um relógio de pulso, contando os batimentos cardíacos dentro de um minuto.

O pulso foi a principal ferramenta diagnóstica entre os chineses antigos. Estes médicos não se

\footnotetext{
1. Acadêmica do 3ํan ano da Faculdade de Medicina da USP.

2. Orientador. Doutor pela Universidade de São Paulo. Médico Assistente do Serviço de Clínica Médica do Hospital das Clínicas da FMUSP. Professor colaborador da Faculdade de Medicina da USP.

Endereço para correspondência: Departamento cientifico do CAOC. Faculdade de Medicina da Universidade de São Paulo. Av. Dr. Arnaldo, 455 - Subsolo. 01246-903 São Paulo -SP email: moara_ramos@hotmail.com
} 
aprofundavam no histórico nem efetuavam exames físicos completos. Eles se limitavam a tomar o pulso de maneiras diversificadas e apresentar uma longa lista de variações, cada qual com um significado específico, pois o pulso indicava o fluxo do elemento vital, formado pela união de yin e yang com o sangue.

\section{O Microscópio}

Provavelmente, o primeiro microscópio elementar foi criado por Johannes e Zacharius Jansen de Middelburg, Holanda em 1590. Em 1610, Galileu Galilei adaptou o telescópio para observar pequenos objetos.

Mas o microscópio de fato foi criado por Antony van Leeuwenhoek (1632-1723) de Delft, Holanda, em 17 de setembro de 1683, o que quase dois séculos mais tarde propiciou grandes descobertas na Medicina.

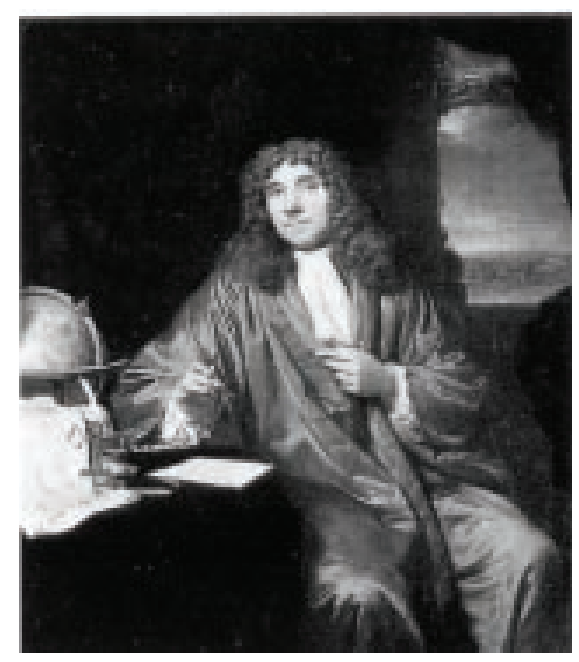

Antony van Leeuwenhoek

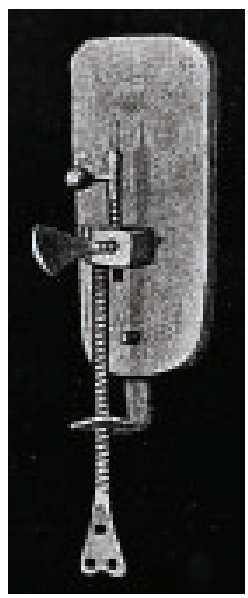

Com a morte de pai em 1648 o jovem Antoine, aos 16 anos, parou de estudar e foi trabalhar numa fábrica de tecidos em Amsterdã, como vendedor. Para controlar a qualidade dos fios, eram usados lupas ou contra-fios. Ele, então, começou a usar lentes para contar as linhas dos tecidos e foi se aperfeiçoando progressivamente. Seus microscópios (mais de 500 por ele criado) tinham apenas uma lente e aumentavam até 200 vezes.

O microscópio de Leeuwenhoek. capilares de Malpighi.

Em 17 de setembro de 1683 descreveu o material extraído de seus dentes, de duas mulheres (provavelmente sua esposa e filha) e de dois homens que nunca tinham escovado os dentes e assim fez a primeira descrição de bactérias. Na realidade ele descobriu as bactérias, os protistas, os espermatozóides, as células sanguíneas, os nematóides microscópicos, entre outros.

\section{A percussão}

Leopold Auenbrugger (19 de novembro de1722-1809) aprendeu a percutir com seu pai, um taberneiro de Gratz,na Áustria, que batia com a ponta dos dedos nos barris de vinho para saber sua quantidade. Comparando o tórax a um tonel, Auenbrugger teve a idéia de aplicar o mesmo método para o diagnóstico do derrame pleural e outras afecções pulmonares.

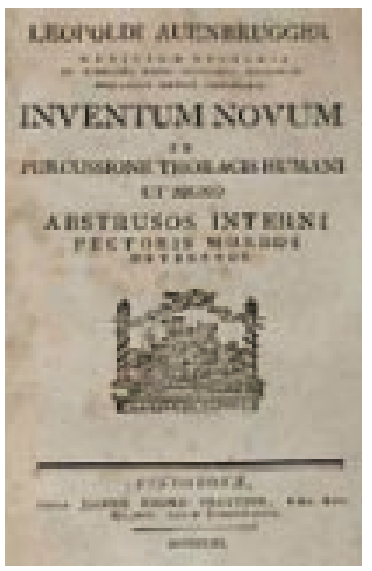

A percursão por Leopold von Auenbrugger.

No Hospital Espanhol de Viena, onde trabalhava, desenvolveu as suas observações com comprovações de necrópsia e, após sete anos de experiência, publicou um pequeno livro de 95 páginas intitulado Inventum novum ex percussione thoracis humani ut signo abstrusos interni pectoris morbos detegendi, (Vindobonae 1761). Seu trabalho despertou pouco interesse, até mesmo em Viena, e só se tornou conhecido e passou a fazer parte do exame clínico após sua tradução para o francês, em 1808, por Jean Nicholas Corvisart (1755-1821), médico de Napoleão. Corvisart era obsessivamente dedicado, chegando a ficar 6 horas auscultando pacientes, e tinha no Dr Stoll, professor de clínica de Viena, grande admiração. Foi Stoll que, após 15 anos da descrição da percussão, tratando de pneumonia, escreveu que a zona pulmonar afetada não oferece ressonância à percussão, ou que tal ressonância é sumamente fraca, comparada com as regiões sãs do órgão. 
Piorry, em 1828 deu exatidão a esta revolucionária arma propedêutica, criando o organografismo ou organometrismo, limitando-se todos os órgãos internos. Skoda, em 1839 modernizou a percussão, mas dedicou-se mais à cardiologia, sendo o criador dessa especialidade. Galeno, fundador da fisiologia experimental, também preocupou-se em obter sons abdominais para diferenciação entre pneumatose intestinal e ascite.

Foram tentados alguns aperfeiçoamentos na percussão, porém, ao contrário da ausculta, os inventos foram fadados ao insucesso. Antes de Piory só se percutia com uma mão.A partir daí duas mãos foram usadas. Uma delas, passou a ser substituída pelo plessímetro, pequena placa oval de marfim revestido de goma elástica (Trosseau), borracha endurecida (Louis, Seitz, Baas), couro (Burne) ,vidro (Hesse de Sonnstein), metal (Traube), madeira (Bufalini), etc. A intenção deste instrumento não é clara,mas imagina-se que seja pelo pudor do toque com a mão espaldada no doente. Esta evolução funcionou com a ausculta, porém, hoje o plessímetro é peça de museu. Wiltrich, em 1841, sofisticou ainda mais esta técnica, criando um martelinho para se usar no lugar do dedo. Felizmente, Torres Homem difundiu o processo digital.

\section{A ausculta}

René Theóphile Hyacinthe Laënnec (17811826), aluno de Covisart, descreveu a técnica de Hipócrates para ausculta de ineficaz, indelicado, e desagradável (colocando-se o ouvido sobre o peito). Em 1816, examinando uma jovem de seios avantajados, enrolou uma folha de papel e ouviu a uma distância decente, inventando o estetoscópio. Substituiu posteriormente a cartolina por um tubo de madeira e deu a esse dispositivo o nome de estetoscópio (de stethos, peito + skopein, ver, examinar). O invento do estetoscópio pode ter vindo da observação de dois garotos brincando. Estavam cada um de um lado de uma tábua de um balanço e com um alfinete um arranhava um lado e o outro encostava o ouvido no outro lado e combinavam um código telegráfico. Os sons caminhavam pelo cilindro de madeira de Laënnec do mesmo modo que faziam na tábua do balanço.

Laennec trabalhava no Hospital Necker, em Paris, onde eram internados muitos doentes do tórax, principalmente tuberculosos. Durante três anos Laennec trabalhou arduamente procurando comprovar nas necrópsias a validade dos seus achados estetacústicos. Em 1819 publicou o seu clássico Tratado de auscultação mediata e das doenças dos pulmões e do coração, no qual descreveu toda a semiologia do tórax em diferentes enfermidades. Muitos termos novos foram por ele criados para descrever as modalidades de ruídos que ouvia.

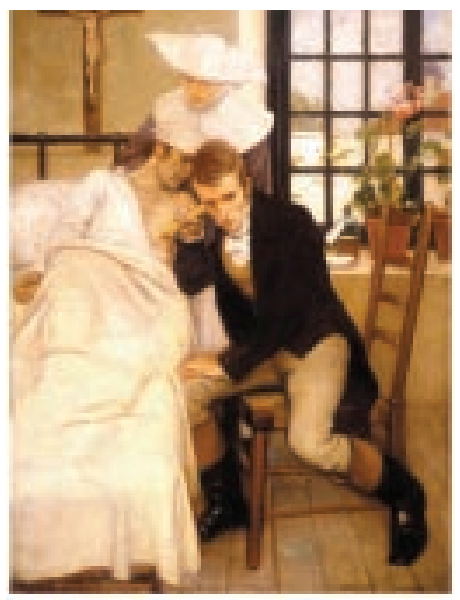

René Theóphile Hyacinthe Laënnec e o estetoscópio.

Morreu aos 45 anos de idade, de tuberculose pulmonar, no mesmo ano em que saía a segunda edição ampliada de seu livro. Teve sua doença agravada com o trabalho da publicação e falou uma frase marcante: "sei que arrisco minha vida, mas espero que o livro que estou escrevendo seja mais importante que a vida de um simples mortal, e é minha obrigação terminá-lo, custe o que custar".

O estetoscópio se tornou o símbolo do clínico, assim como o bisturi se tornou o símbolo do cirurgião. O estetoscópio foi um marco divisório de duas épocas na história da Clínica Médica. Diversos modelos de estetoscópios foram construídos no decorrer do século XIX e início do século XX até chegarmos ao modelo flexível biauricular atual.

\section{O termômetro}

Galileu (15 de fevereiro de 1564-1642) foi mais conhecido por derrubar as teorias aristotélicas de que a Terra é o centro do universo, mas foi ele, também, o inventor do termômetro. Sanctorius aperfeiçoou-o para ser usado em humanos, mas tinha $33 \mathrm{~cm}$ e precisava ser chupado por 20 minutos.

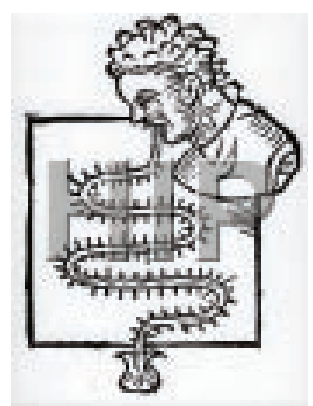

Galileu e o termômetro. 
O primeiro grande clínico a incorporar o termômetro em seu dia-a-dia foi Boerhaave. Seu uso só foi difundido, entretanto, a partir da Alemanha, graças a Ludwig Traube (1818-1876) e Karl August Wunderlich (1815-1877). Wundrelich analisando 25 mil pacientes com diversas doenças, propôs a aferição da temperatura para se descobrir "as leis que regem as enfermidades".

Traube foi o primeiro professor na Europa a dispor de uma enfermaria para ensino da Semiologia e o primeiro a publicar um gráfico de temperatura. Seguiram-se os estudos de Wunderlich sobre a termometria clínica, que modificaram inteiramente o conceito sobre as febres, que eram vistas como doenças e passaram a ser consideradas como sintomas.

Daniel Gabriel Fahrenheit construiu uma escala de medidas de temperatura, usando mercúrio, dando mais precisão às medições.

Thomas Clifford Albutt (1836-1925) observou que, embora os termômetros já fossem bastante utilizados pelos médicos, eles eram desajeitados e de formato pouco cômodo; às vezes requeriam mais de 20 min para uma leitura confiável. Por volta de 1866, Allbut inventou o termômetro clínico de mercúrio, muito menor que os modelos da época. Este novo termômetro requeria apenas 5 min para tirar a temperatura. O termômetro de Allbutt ainda é o termômetro clínico dominante, apesar da recente introdução do termômetro digital.

\section{O esfingmomanômetro}

Ao termômetro e ao estetoscópio, no final do século XIX, somaram-se aos acessórios médicos o medidor de pressão arterial.

Já no Egito Antigo reconhecia-se a importância do pulso sanguíneo como medida significante no conhecimento das enfermidades do coração, tal como informa o papiro de Ebers, colocando-se os dedos sobre varias partes do corpo verifica-se que o coração "fala" através dos vasos.

No entanto, coube a dois médicos da Alexandria, Herofilo (300 a.c.) e Erasistrato (310 a.c.) a descrição do pulso arterial. Este, considerado o "fundador da fisiologia" considerou que o "coração dá origem ao espírito vital que é levado pelas artérias a todas as partes do corpo". Já Herófilo foi o fundador da "doutrina do pulso" como descrito anteriormente.

Um século depois de William Harvey ter publicado seus estudos sobre circulação é que o reverendo Stephen Hales (1677-1761) fez a primeira medição da P.A. de um animal, como assim o descreveu em 1733, em seu primeiro experimento: "Em dezembro, eu imobilizei uma égua, com 1,4m de altura e cerca de 14 anos, que tinha uma fístula na sua virilha. Não era nem forte, nem fraca. Tendo aberto sua artéria crural esquerda em cerca de $7,6 \mathrm{~cm}$ a partir de seu ventre, eu inserí um tubo de cobre com $0,4 \mathrm{~cm}$ de calibre e, através de um outro tubo de cobre que estava firmemente adaptado ao primeiro, eu fixei um tubo de vidro de, aproximadamente, o mesmo diâmetro, com 2,7m de comprimento.

Então, soltando a ligadura da artéria, o sangue subiu a $2,5 \mathrm{~m}$ no tubo de vidro, acima do ventrículo esquerdo do coração... quando atingia sua máxima altura, oscilava $5,7,5$ ou $10 \mathrm{~cm}$ após cada pulsação. Então eu tirei o tubo de vidro, e deixei o sangue jorrar livremente, quando a altura máxima atingida pelo jato não era mais do que $61 \mathrm{~cm}$. Eu medí como o sangue jorrava da artéria, e após cada quart $(1,141)$ que saía, eu refixei o tubo de vidro na artéria para ver o quanto a força do sangue tinha diminuído; isto eu repeti até 8 quart, quando a força tornou-se então fraca... Após a morte do animal, quase 3 quart do sangue permanecia no seu corpo, o qual somado com o que havia sangrado, totaliza 20 quart (22,81), o que, numa baixa estimativa, podemos calcular como a quantidade de sangue circulante de um cavalo"

Seus estudos, no entanto, só foram relembrados cerca de 100 anos depois quando Jean Leonard Poiseuille resolveu melhorar o manômetro inventado pelo religioso, criando assim o hemodinamometro.

O "Hemodinamômetro" consistia em um tubo em U, com $20 \mathrm{~cm}$, parcialmente cheio de mercúrio, conectado a uma cânula cheia de $\mathrm{KCO}_{3}$ (anticoagulante) que, por sua vez, era diretamente inserida na artéria do animal em experiência, medindo sua PA de uma maneira invasiva, através da diferença em mm, observada ao nível de $\mathrm{Hg}$, no tubo em U. Poiseuille cateterizou artérias de $2 \mathrm{~mm}$ e demonstrou que a PA também era mantida nas pequenas artérias, estudou também a viscosidade sanguínea e a resistência do sistema cardiovascular. O Hemodinamômetro foi usado apenas em laboratório pois não tinha uso clinico pratico. Ainda assim, serviu como modelo para todos aparelhos de medir pressão arterial que se seguiram.

Em 1834, J. Herrisson (medico) e P. Gernier (engenheiro) fizeram a primeira tentativa de quantificar numericamente a pressão arterial de maneira indireta. A Invenção deles consistia em uma coluna graduada em $\mathrm{mm}$ com um reservatório de mercúrio na base. Este aparelho era colocado sob o pulso do paciente e, com o peso do $\mathrm{Hg}$, a artéria era comprimida e sua pulsação movimentava a coluna. Isto é, transformava uma sensação tátil em uma impressão visível. Dessa forma, foi inventado o Esfingmomanômetro (gr. Sphygmos = pulso), no 
entanto, a dificuldade de quantificar a oscilação do pulso levou ao abandono do instrumento.

A partir da inovação de Pouiseuille com o Hemodinamometro, Karl Ludwig (1816-1895) foi capaz de desenvolver o quimógrafo (gr.Kyma=onda). Em 1847, colocou sobre a coluna de mercúrio um flutuador, conectado a uma agulha de inscrição, que deslizava sobre um cilindro giratório esfumaçado . Dessa maneira, Ludwig foi o primeiro a inscrever ondas de Pressão Arterial.

Cerca de 8 anos depois, Karl Vierordt (18141884) postulou que se a pulsação cessasse, seria possível medir a PA de forma indireta e não invasiva. Para isso, adaptou ao quimógrafo um sistema de pesos que bloqueava a pulsação da artéria radial, levando à parada dos movimentos da agulha inscritora do quimógrafo. Embora seu grande e pesado aparelho tenha sido de pouca utilidade, o grande mérito de sua invenção foi o principio de que era necessário impedir a propagação das ondas esfíngmicas, por meio da obstrução da artéria, para que se determinasse a pressão sistólica.

A partir da premissa de Vierordt, Samuel Sigfried Ritter von Basch (1837-1905) inventou três aparelhos de medir a PA. O mais simples deles, e também o mais parecido com o que hoje chamamos de Esfigmomanômetro, consistia em uma bolsa de borracha inflável, cheia de água, com um bulbo de $\mathrm{Hg}$ no seu interior, ligado a uma coluna de $\mathrm{Hg}$ graduada. A bolsa de borracha comprimia a artéria radial, o que provocava elevação na coluna de $\mathrm{Hg}$, determinando a Pressão Sistólica ${ }^{5}$. Von Basch foi o primeiro médico a observar que, nos indivíduos idosos, ou com arteriosclerose, a PS era mais elevada do que na população normal, o que ele chamou de "aterosclerose latente", iniciando a conceituação de hipertensão arterial (HA) essencial ${ }^{2}$. $\mathrm{Na}$ época, o conceituado jornal inglês British Medical Journal não pode deixar de publicar uma nota sobre o mais novo invento "nós empobrecemos nossa sensibilidade e enfraquecemos nossa perspicácia clínica”, provando que a aceitação do esfingmomanometro pelos clínicos contemporâneos a esse invento não foi nada uniforme, muito pelo contrario, o que encontrou foi uma enorme resistência.

Anos mais tarde, um médico italiano Scipione Riva-Rocci (1863-1937) descreveu "um novo esfingmomanômetro". Em dezembro de 1896, RivaRocci, partindo de conceitos clínico-fisiológicos, escreveu "do ponto de vista clínico, nós pesquisamos o valor e a variação da pressão sangüínea arterial, por dois enfoques principais: $01^{\circ}$, trata de conhecer o impacto que a PA exerce sobre as paredes dos vasos e tecidos adjacentes, o qual permite julgar o grau de resistência dessas paredes e tecidos e, sobretudo, da maior ou menor probabilidade de ruptura dessa parede; o 2으. por medir a função cardíaca com todas as suas repercussões circulatórias e biológicas. A meu juízo, nós não dispomos nem de métodos, nem de instrumentos que permitam desenvolver os postulados da clínica".

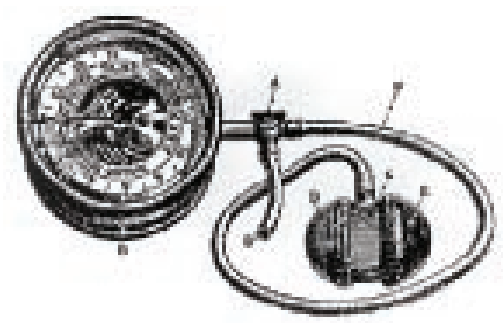

O esfinomanômetro de Samuel Sigfried Ritter Von Basch.

Visando criar um aparelho sensível, portátil, de fácil manejo e de aplicação incruenta mas acurada; tentando, ao mesmo tempo, resolver o problema da técnica de Vierordt e de von Basch, de compressão unilateral da artéria radial, Riva-Rocci escolheu a artéria umeral (por "ser um ponto mais perto da aorta, sem circulação colateral, e que expressa melhor a carga total para impedir a propagação da onda esfígmica") para utilizar em seu aparelho. Seu invento compunha-se de duas partes, uma destinada a exercer compressão sobre igualmente todos os lados da artéria, e outra que permitia medir a pressão exercida. Chamou-o de "angioparatlibometro".

Sua técnica consistia de um manguito, de 4 a $5 \mathrm{~cm}$ de largura, que cobria o braço em todo a sua circunferência, e que era inflado pela dupla bola de Richardson, entre os quais estava interposto um manômetro de coluna de $\mathrm{Hg}$ (fig. 5). Inflava-se o manguito, até total desaparecimento do pulso radial, seguindo-se desinflação, até o seu reaparecimento, quando então era medida a PS, no manômetro.

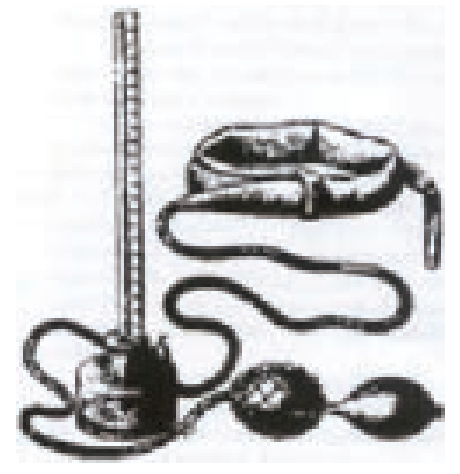

Esfigmomanômetro de Scipione Riva Rocci.

Riva-Rocci coroou, assim, o fim de uma era de pesquisas em busca de um método clinico simples 
de avaliação de P.A. A medição da Pressão Sistolica foi, de maneira inquestionável, assim definida. A partir de então, as pesquisas se concentraram em definir a pressão diastolica.

A detecção definitiva da Pressão Diastolica foi feita por Nicolai Segeivich Korotkoff (1874-1920). Baseado na experiência adquirida como cirurgião vascular, nas guerras "Rebelião dos Boxer", na China (1900), e na Rússia-Japão (1904), e também nos estudos de Nikolai Ivanovich Pirogoff (1810-1881) sobre ausculta de fístulas arteriovenosas, e tumores vasculares, Korotkoff apresentou, na Academia Imperial Médica Militar de São Petersburgo, em dezembro de 1904, sua descoberta do método auscultatório do pulso. Em apenas 178 palavras russas, descreveu: "Baseado nas observações de que, sob completa constrição, a artéria não emite sons... O aparelho de Riva-Rocci é colocado no braço e sua pressão é rapidamente aumentada até bloquear completamente a circulação abaixo do manguito, quando não se ouve nenhum som no estetoscópio de criança (manoauricular). Então, deixando a pressão do manômetro de $\mathrm{Hg}$ cair até certa altura, um som curto e fraco é ouvido, o que indica a passagem de parte da onda de pulso sob o manguito, caracterizando a pressão máxima. Deixando a pressão do manômetro cair, progressivamente, ouvese o sopro da compressão sistólica, e que se torna novamente, som. Finalmente, todos os sons desaparecem, o que indica livre passagem do fluxo sangüíneo ou, em outras palavras, a PA mínima ultrapassou a pressão exercida pelo manguito. Este momento corresponde a PA mínima. As experiências mostraram também, que o primeiro som aparece 10 a $12 \mathrm{mmHg}$ antes da palpação do pulso radial".

Foi assim, que no inicio do século XX, um medico russo revolucionou a medicina, criando o método que até hoje utilizamos para controlar e diagnosticar uma das doenças de maior prevalência na população mundial.

\section{A radiografia}

Wilhelm Konrad Röntgen (1845-1922), professor de física em Würzburg, na Bavária, em 8 de novembro de 1895, descobriu a radiografia enquanto trabalhava em casa sobre os raios catódicos inventados pelo inglês William Crookes (1832-1919). O aparelho consistia em um tubo de vidro, dentro do qual um condutor metálico aquecido emitia elétrons (raios catódicos) em direção a outro condutor. Na ocasião havia perto do tubo uma placa de um material fluorescente, chamado platino cianeto de bário, que brilhou no momento em que o aparelho foi ligado. O brilho sumia ao desligar-se o tubo. Por volta de seis semanas, Röntgen trancou-se em seu laboratório a fim de entender o fenômeno.

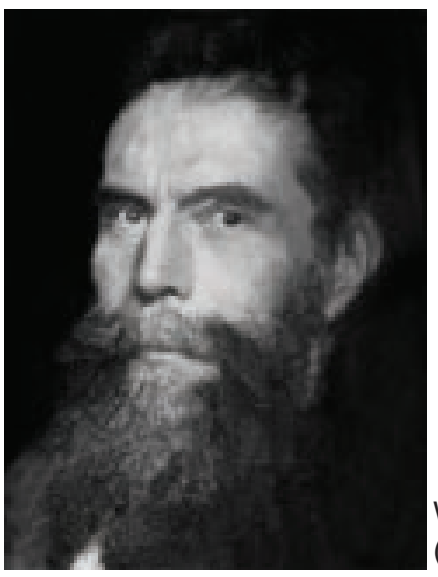

Wilhelm Konrad Röntgen (1901)

No dia 22 de dezembro o cientista fez a irradiação atravessar por 15 minutos a mão de sua mulher Bertha, atingindo do outro lado uma chapa fotográfica. A sombra dos ossos de sua esposa puderam ser vistos na revelação da chapa fotográfica, e foi assim que tomou lugar a primeira radiografia da história da medicina.

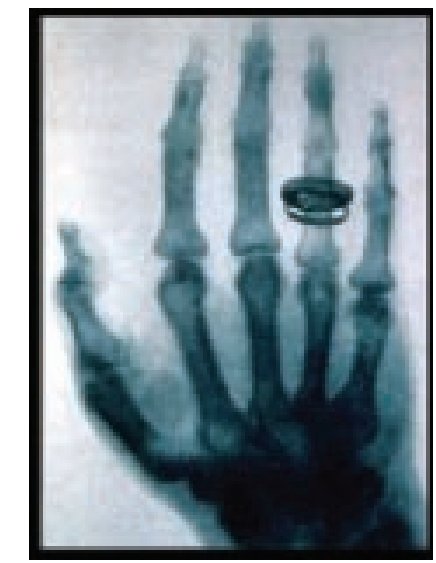

A mão de Bertha - primeira radiografia.

O raio $X$ foi assim nomeado porque inicialmente não conhecia-se a natureza de suas propriedades físicas. O raio-X é uma onda de alta energia, cujo comprimento de onda é muito curto, da ordem de $10^{-}$ ${ }^{12} \mathrm{~m}$ (um picômetro), e sua freqüência é da ordem de $10^{16} \mathrm{~Hz}$. O comprimento de onda do raio-X está próximo ao do raio- $\gamma$, que é radioativo. Com este comprimento de onda muito curto, estes raios tem a capacidade de penetrar na matéria, o que possibilita sua utilização no estudo dos tecidos do corpo humano.

Roentgen, no dia 23 de janeiro, fez sua 
demonstração publica na Sociedade Médico-Física de Würzburg. A noticia causou sensação mundial e marcou toda uma época. A receptividade foi tal que foram instalados, por exemplo, equipamentos de Raios-X em sapatarias para que os clientes pudessem examinar os seus pés dentro dos sapatos. Vendiam-se roupas intimas à prova de raio- $x$ e foi aprovado, até mesmo, um projeto de lei que proibia o uso de binóculos de raio-x em teatros.

Encontrou-se as mais variadas utilidades para o Raio-x. Na guerra hispânico-americana, por exemplo, os cirurgiões usaram os raios $X$ para localizarem as balas nos corpos dos soldados feridos.

No Brasil, o Raio-x chegou com o médico mineiro José Carlos Ferreira Pires, que levou a novidade para Formiga, em 1897. Aqui também o raio-x foi utilizado como instrumento de guerra, quando, na guerra de canudos, o professor Alfredo de Brito utilizou a radiografia para localizar projéteis da arma de fogo.

Outro brasileiro, Manoel de Abreu, foi o responsável por desenvolver a abreugrafia, que revolucionou o diagnóstico e tratamento da tuberculose, através de um método de diagnóstico coletivo, e o primeiro no mundo a falar sobre Densitometria Pulmonar.

Abreu foi o responsável por criar um método de diagnostico radiológico a baixo custo, a fluorografia (mais tarde denominada abreugrafia), o que permitiu o seu acesso à população em geral. Abreu sistematizou o novo método, divulgou-o e utilizou-o em massa no combate à tuberculose.

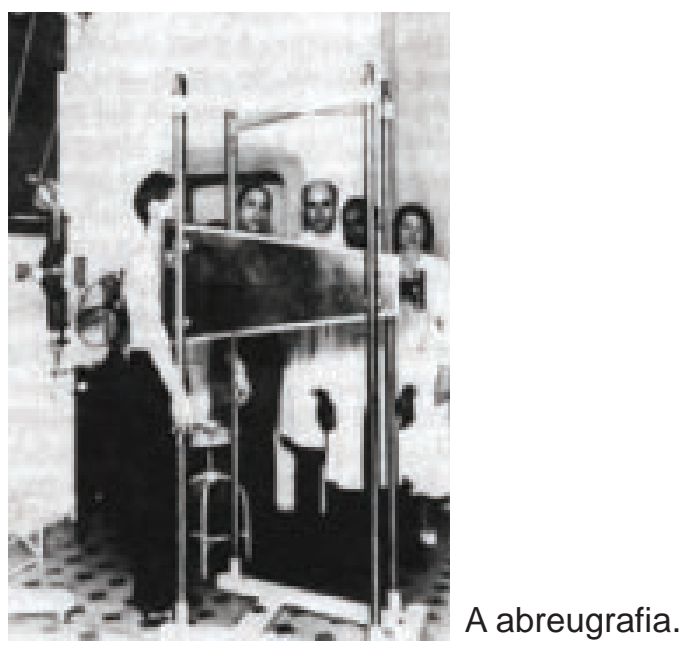

Em Paris, aperfeiçoou-se na radiologia pulmonar e desenvolveu a densimetria, isto é, a mensuração das diferentes densidades. Coube a Abreu o mérito de salientar a importância da tonalidade da sombra pulmonar, como um elemento indispensável à própria caracterização da imagem radiológica. Ao invés de termos vagos, imprecisos, para exprimir as diferentes nuances de tonalidades das sombras, deve-se fazer a mensuração delas e exprimi-las em graus. Para tanto, utiliza $0 \mathrm{~cm}^{3}$ de água como unidade densimétrica, como elemento de comparação, pela razão de a água apresenta uma opacidade quase idêntica à dos tecidos orgânicos.

$O$ efeito nocivo do raio- $X$ só foi reconhecido muito depois da sua descoberta. Muitas pessoas morreram da radiação ou adquiriram leucemia. Uma das primeiras vitimas brasileiras da irradiação foi Álvaro Alvim, que perdeu progressivamente dedos, mão e antebraço das mãos direita e esquerda, falecendo em 1928 de leucemia. Este homem foi o primeiro a instalar um aparelho de Raio-X no Rio de Janeiro (1897). Foi ele, também, quem radiografou o primeiro caso de xifópagas no mundo, identificando os órgãos das irmãs Rosalina e Maria, que foram separadas, com sucesso, pelo cirurgião Chapot Prevost. Assim, aos poucos, as pessoas começaram a tomar conhecimento dos efeitos nocivos da radiação e passaram a se proteger contra ela.

\section{O Eletrocardiograma}

O termo elétrica foi introduzido por William Gilbert, medico da rainha Elizabeth I e criador da "filosofia magnética", para os objetos que tinham eletricidade estática. Foi ele um dos primeiros a verificar que alguns materiais, quando atritados, se atraem e outros não. Os primeiros, ele denominou de elétricos e os demais de não-elétricos. O termo elétrico veio do grego para o âmbar (eletra).

Jan Swammerdam, em 1664, estimulou um nervo de rã morta, fazendo com que o músculo se movimentasse. Este experimento fez com que caísse por terra a teoria defendida por René Descartes dos "espíritos animais", na qual deveria haver cérebro para haver movimento. Até 1780 , os experimentos com eletricidade se resumiam à eletrostática. $A$ única maneira prática de se gerar eletricidade era por meio de aparatos eletrostáticos usando algum processo de atrito, sem, contudo, ser possível armazenar a eletricidade produzida. Entre os vários engenhos para armazenar Eletricidade estática destaca-se a Jarra de Leyden, desenvolvida por um físico holandês. A Jarra de Leyden era constituída por um recipiente de vidro forrado interna e externamente por uma camada metálica, e agia tal qual um capacitor, com o poder de produzir violentas descargas elétricas.

A exemplo do ocorrido um século antes, Luigi Galvani observou, em 1791, a contratura de uma rã dissecada, quando tocada por um metal. Esta descoberta foi acidental e assim descrita: "Eu dissequei e preparei uma rã do jeito habitual e 
enquanto fazia outras coisas, eu a deixei numa mesa na qual estava uma máquina elétrica a certa distância. Então uma pessoa tocou acidentalmente no aparelho e nos nervos crurais da rã com o bisturi e os músculos da pata contraíram repetidamente como se fosse uma cãimbra intensa". Galvani erroneamente acreditava que a fonte de eletricidade era o tecido animal da perna da rã, e que o fenômeno observado era semelhante à descarga de uma Jarra de Leyden. Criou assim, em 1971, a teoria da Eletricidade Animal. Deu nome também ao Galvanômetro, instrumento que mede (e registra) a eletricidade. $O$ eletrocardiógrafo nada mais é que um galvanômetro sensivel.

Alessandro Volta (1745-1827) professor de filosofia natural na Universidade de Pavia, na Itália, repetiu vários experimentos de Galvani e logo se convenceu que a fonte de eletricidade era devido ao contato dos dois metais, e que os músculos e tecidos da perna da rã serviam apenas como um detector. Volta demonstrou que os músculos poderiam se contrair por estimulação elétrica e criou assim a fonte de inspiração para que Mary Shelley, em 1818, criasse o famoso Frankenstein.

Em 1819, o físico Hans Christian Oersted (1777-1851) observou o movimento de agulha com a corrente elétrica de um arame de platina. Um ano depois, Johann Schweiggen, amplificou o movimento da agulha e propôs a existência de um campo magnético, mais tarde provado por Michael Faraday. Schweiggen inventou o galvanômetro (e o ECG nada mais é que um galvanômetro), e anunciou sua descoberta na Universidade de Halle em 16 de setembro de 1820.

Carlo Mateucci, em 1842, mostrou que uma corrente elétrica acompanha cada batimento cardíaco. No ano seguinte, Emil Dubois-Reymond, usando um galvanômetro super-sensível, com 24000 voltas $(5 \mathrm{~km})$, demonstrou o potencial de ação das fibras musculares. Em 1850, Hoffa descreveu uma ação bizarra dos ventrículos, mais tarde chamada de fibrilação ventricular. Discute-se se o primeiro eletrocardiograma humano fora registrado por Alexandre Muirhead, em 1869-70, no hospital de São Bartolomeu.

Em 1872, Gabriel Lippmann inventou o eletrômetro capilar, que foi o precursor do eletrocardiógrafo. Este aparelho foi usado para registrar atividade cardíaca de uma rã em 1876 por Marey, e em 1878, por John Burder Sanderson e Frederick Page, que demonstraram 2 fases (mais tarde conhecidas por QRS e T). O eletrômetro capilar foi aperfeiçoado por Arsène d'Arsonval e Marcel Deprez, e serviu de base para os galvanômetros modernos. O eletrômetro capilar de Lippmann consistia em um tubo de vidro, terminado por uma extremidade capilar muito fina, e cheio de mercúrio. A ponta do capilar mergulhava verticalmente em uma cuba contendo ácido sulfúrico diluído, o qual repousava sobre uma camada inferior de mercúrio. Os eletrodos eram ligados ao ácido sulfúrico e ao mercúrio, respectivamente, e as variações de potencial estabelecidas entre eles modificavam as forças de tensão superficial e faziam com que o menisco de separação, entre o mercúrio e o ácido sulfúrico, se deslocasse para cima ou para baixo no tubo capilar. A zona de separação dos dois líquidos era fortemente iluminada, e a imagem do menisco, grandemente aumentada por meio de lente apocromática, era projetada sobre uma fenda vertical, por trás da qual deslizava, em velocidade constante, uma placa fotográfica.

Em 1887, o fisiologista britânico Augustus D. Waller publicou o primeiro eletrocardiograma humano, do técnico de laboratório Thomas Goswell. Waller demonstrava sua técnica com seu cachorro Jimmy, que pacientemente ficava com suas patas numa jarra com salina.

William Bayliss e Edward Starling, em 1891, aperfeiçoaram o eletrômetro capilar. Eles conectaram os terminais no braço direito e no tórax do paciente $\mathrm{e}$ mostraram uma variação trifásica acompanhando (ou precedendo) cada batida do coração. Estas deflexões mais tarde foram chamadas de P, QRS e T. Demonstraram ainda um intervalo de cerca de $0,13 \mathrm{~s}$ entre a despolarização do átrio e a do ventrículo.

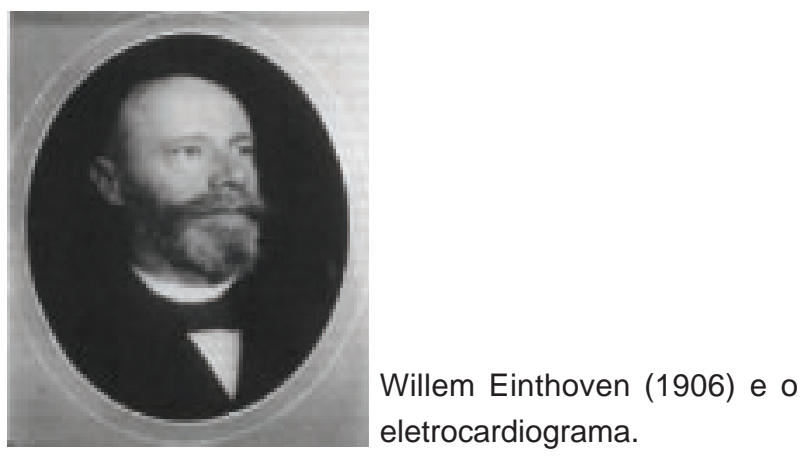

Cerca de 4 anos mais tarde, William Einthoven, considerado por muitos o pai do eletrocardiograma, descreveu cinco fases diferentes da corrente elétrica e nomeou-as de $P, Q, R, S, T$. Continuou seus estudos, até que, em 1912 descreveu um triangulo que leva o seu nome, com as derivações I, II e III. Einthoven também foi o responsável pela invenção de um novo galvanômetro. Utilizando-se do conhecimento de Deprez e d'Arsonval, ele pôde criar um novo aparelho usando flamento de quartzo recoberto por prata. Sua criação pesava cerca de 270 $\mathrm{Kg}$ e com ela pôde publicar o primeiro registro eletrocardiografico. Em março de 1906, Einthoven 
inaugurou o telecardiograma, quando, por meio da rede telefônica, transmitiu um ECG do hospital a seu laboratório, há cerca de 1,5 Km de distancia. Neste mesmo ano publicou de forma organizada ECG normais e anormais, ou seja, registros que continham hipertrofias atriais e ventriculares, onda $U$, bigeminismo, flutter atrial e bloqueios cardíacos. Pela invenção do eletrocardiógrafo recebeu o premio nobel em 1924.

Nicolai e Simmons, em 1909, descreveram alterações eletrocardiográficas durante a angina. Alguns anos mais tarde Harold Pardee, de Nova York, publicou o primeiro eletrocardiograma de um infarto agudo do miocárdio, descrevendo com precisão atual suas alterações.

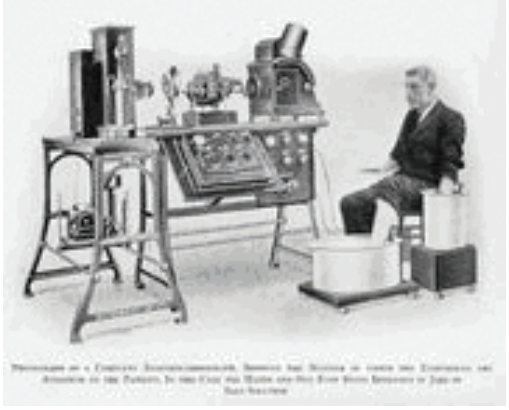

Eletrocardiograma por Einthoven.

Já as derivações unipolares foram criadas por Frank Wilson, quando, em 1934, usou fios elétricos no braço direito, braço esquerdo e perna esquerda, com resistores de $5000 \mathrm{Ohm}$. Estas derivações combinadas agiam com a terra, que era assim o terminal negativo do eletrocardiógrafo. Wilson definiu as derivações $\mathrm{VR}, \mathrm{VL}, \mathrm{VF}$, nas quais $\mathrm{V}$ era voltagem (do eletrodo unipolar). Já as derivações de V1 a V6 foram criadas 4 anos mais tarde. Emanuel Goldberger, em 1942, aumentou a voltagem das derivações unipolares de Wilson em $50 \%$, criando assim as derivações que são usadas hoje em dia, aVR, aVL e aVF.

O primeiro aparelho de ECG portátil foi criado em 1928 pela companhia de Frank Sanborn (depois comprada pela Hewlett-packard). Ele pesava $22,5 \mathrm{Kg}$ e era movido por uma bateria de automóvel de $6 \mathrm{~V}$.

Em 1906, Cremer descreveu o primeiro ECG transesofageano. Esta técnica, no entanto, só foi desenvolvida nos anos 70 a fim de que se pudesse diferenciar arritmias atriais. Em 1931, Charles Woferth e Francis Wood descreveram o uso de exercício para provocar angina de registro no ECG. No entanto, na época, tal prática foi afastada por ser considerada muito perigosa. Cerca de três décadas depois, Robert Bruce padronizou o ECG de esforço, no protocolo que hoje é conhecido com protocolo de Bruce, e tornou-o uma ferramenta na clinica cardiológica. Como ele mesmo afirmava "você nunca vai comprar um carro usado sem fazer um teste e ver como a máquina funciona durante uma corrida. É o mesmo com o coração". Em 1949. Norman Jeff Holter desenvolveu a técnica de monitorização continua de armazenamento dos dados do coração. Esse teste, que é conhecido pelo nome do medico que o desenvolveu (Holter) é até hoje conhecido e utilizado no mundo todo.

Ramos M, Gapit VL, Lichtenstein A. Clinical instruments development. Rev Med (São Paulo). 2007 jan.-mar.;86(1):52-60.

ABSTRACTS: This article is about the clinical instruments that makes part of the day by day of the medical practice e how have they become so essencial in the routine of the health staff.

KEY WORDS: Equipments and supplies. Physicians.

\section{REFERÊNCIAS}

http://publicacoes.cardiol.br/caminhos/016/default.asp

http://www.hcnet.usp.br/inrad/departamento/graduacao/ aula/Fisica\%20basica\%20das\% 20radiografias\%20 convencionais.doc

http://www.scielo.br/scielo.php?script =sci_arttext\& pid $=$ S0102-35862001000100010 http://inventabrasilnet.t5.com.br/abreug.htm

http://www.discoverybrasil.com/guia_tecnologia/ tecnologia_medica/raiosx/index.shtml

http://www.rijo.pro.br/Rijo\%20Cap4A.pdf

http://publicacoes.cardiol.br/caminhos/015/default.asp 